\title{
Indirect Epistemic Reasons and Religious Belief
}

\section{Kirk Lougheed and Robert Mark Simpson}

\begin{abstract}
If believing $\mathrm{P}$ will result in epistemically good outcomes, does this generate an epistemic reason to believe P, or just a pragmatic reason? Conceiving of such reasons as epistemic reasons seems to lead to absurd consequences, for example, allowing that someone can rationally hold beliefs that conflict with her assessment of her evidence's probative force. We explain why conceiving of such reasons as epistemic reasons can avoid this and other intuitively unwelcome results. We also suggest a positive case for conceiving of such reasons as epistemic reasons, namely, that they exhibit a kind of interpersonal normative parity that's typical of epistemic reasons but not pragmatic reasons. We then discuss connections between these issues and religious belief, suggesting that there are sometimes indirect epistemic reasons for religious belief, and that certain characterisations of religious belief may be instructive in thinking about what's involved in taking account of indirect epistemic reasons.
\end{abstract}

\section{Introduction}

Religion is a domain of belief in which non-evidential reasons for belief have often been taken seriously as potential sources of justification for people's doxastic attitudes. Consider Pascal's wager, which attempts to identify a pragmatic justification for theistic belief. ${ }^{1}$ If the benefit of having a true belief in God's existence is

\footnotetext{
${ }^{1}$ The wager argument was formulated by Pascal in the $17^{\text {th }}$ century, and it appears in part III of the Pensées, which has been translated and published many times from the $19^{\text {th }}$ century onwards.
} 
eternal joy, and if the cost of having a false belief in God's non-existence is everlasting torment, then this seemingly gives us a significant pragmatic reason to believe in God's existence - or rather, to undertake practices that can nurture a belief in God's existence - independently of our views about the probative force of the evidence that tells for or against theism. The wager is what may be called a 'truth-dependent' pragmatic argument for theism. The pragmatic benefits that it identifies as a reason in favour of theism are ones that will only eventuate if theism is in fact a true belief. There are also 'truth-independent' pragmatic arguments for theism, such as William James's 'will to believe' argument (1912), which claim that various individual and/or social benefits are likely to result from theistic belief, irrespective of that belief's truth or falsity. For James, this supplies us with a pragmatic reason in support of theistic belief - again, a reason whose force is independent of our appraisals of the evidence that tells for or against theism. ${ }^{2}$

Some recent work in epistemology has examined a different type of non-evidential reason for belief, a type of reason that we'll refer to in what follows as an indirect epistemic reason. As a schematic sketch of the type of reason we'll be discussing here, consider a scenario in which the following conditions obtain.

(i) Epistemically good outcomes will ensue, e.g. a significant number of people will come to have true beliefs about a significant number of non-trivial propositions, provided that agent A believes P;

(ii) Whatever countervailing, epistemically bad outcomes that will ensue as a result of A believing P are negligible and/or clearly outweighed by these epistemically good outcomes; and

(iii) A has a reasonable belief that conditions (i) and (ii) hold.

It is clear enough that in a scenario like this A has some kind of a reason to believe that P. ${ }^{3}$ The first question we want to address in this paper is: what's the most appropriate way to characterise the type of reason for belief that $\mathrm{A}$ has in a case like this one, i.e. in a case in which A believes that her believing $\mathrm{P}$ is likely to have indirect epistemic benefits, irrespective of the truth or falsity of the belief itself? Or to express the question another way: if we set aside A's other P-relevant reasons for belief, including her straightforwardly epistemic reasons (e.g. her P-related evidence), do the epistemically beneficial consequences of A's believing P provide

\footnotetext{
2 We borrow the language of truth-dependent and truth-independent pragmatic arguments from Jordan (2014).

${ }^{3}$ Throughout we'll speak in terms of binary doxastic attitudes, on which an agent either believes or disbelieves P. But this is merely for ease of expression. Our claims are intended to apply equally when treating doxastic attitudes as graded credences.
} 
A with an epistemic reason to believe $\mathrm{P}$, or do they merely represent a pragmatic reason for A to believe P?4 It isn't obvious, prima facie, whether it makes most sense to classify these kinds of reasons as epistemic reasons or pragmatic reasons for belief. In the first part of this paper, $₫ 2$, we explain why the former classificatory option has more to recommend it than some authors - in particular Selim Berker - suggest. The very fact that we call these reasons 'indirect epistemic reasons' is an indication of the position we'll be defending, namely, that such reasons can be properly characterised as epistemic reasons of a certain sort.

In the second part of the paper, $₫ 3$, we consider how reflection on indirect epistemic reasons for belief might affect the rational standing of people's beliefs about matters of religion. As we say above, nonevidential reasons for belief have often been taken seriously as potential sources of justification in relation to religious belief, and this is one reason why it makes sense to explore the implications of indirect epistemic reasons for belief in this particular domain. We'll suggest that consideration of indirect epistemic reasons can sometimes provide rational support for religious beliefs. In this part of the paper we also offer some tentative and suggestive reflections on what might be involved in attempting to consciously take account of indirect epistemic reasons as reasons, that is, in consciously factoring the force of such reasons into one's all-thingsconsidered judgments about what doxastic attitudes one ought to hold. In this we indicate some potentially illuminating connections with pragmatic arguments for theism like those of Pascal and James.

\section{Indirect Epistemic Reasons}

\subsection{The alleged irrationality of believing for the sake of indirect epistemic benefits}

There are several authors who grant the possibility of there being indirect epistemic benefits as a result of a person holding a particular belief in particular circumstances, while at the same time insisting that holding the belief in question on the basis of that reason would not be epistemically rational. These authors thus take the

\footnotetext{
${ }^{4}$ Some contemporary epistemologists put pressure on any straightforward distinction between 'purely' epistemic considerations and 'mere' pragmatic considerations; one prominent recent example is Stanley's (2005) work arguing that whether A knows P is partly determined by the practical interests that are a stake for $\mathrm{A}$ in connection with the truth or falsity of $\mathrm{P}$. And of course there is also the entire pragmatist tradition, of which James is a representative, which treats epistemic notions like truth as analysable in terms of some kind of pragmatic considerations. For the purposes of this paper, nonetheless, we will assume what we take to be a fairly widespread and intuitive distinction between mere pragmatic reasons for belief and properly epistemic reasons for belief.
} 
view that indirect epistemic reasons ought to be characterised as mere pragmatic reasons for belief. Consider, for example, a type of case discussed by Marc Moffett (2007) and Catherine Elgin (2010). Suppose an agent working in a research community, A, believes some idiosyncratic thesis, $\mathrm{P}$, and suppose that the community's epistemic aims (e.g. acquiring knowledge in the relevant domain) are likely to be more effectively advanced as a result of this agent holding this unorthodox belief. ${ }^{5}$ In discussing this kind of case, David Christensen says that A believing P in view of these epistemic benefits isn't epistemically rational; if such belief is rational at all, he says, it's merely practically rational. Although "there may well be important epistemic benefits" that result from the agent's eccentric patterns of belief, he says, "the patterns of belief are no more epistemically rational for all that" (2007: 216). Richard Feldman makes a similar point about the epistemic benefits that result from people holding firm in their beliefs in the face of widespread disagreement. "It may be that the search for the truth is most successful if people argue for the things that seem true to them" he says, "but one can do that without being epistemically justified in believing that one's view is correct" (2011: 157). While both authors are happy to say that the attainment of valuable epistemic outcomes as a result of $\mathrm{A}$ believing $\mathrm{P}$ can provide A with some kind of a reason to believe P, their point is that this won't be an epistemic reason.

Berker agrees, and he uses an example from Roderick Firth (1981) and Richard Fumerton (2001) to elicit intuitions about epistemic rationality in support of his view (we've tweaked his example below).

ATHEIST SCIENTIST. Imagine a scientist, S, who is trying to win a major research grant from a funding body that exclusively funds work by researchers who believe in God. S thus knows that she'll only stand a chance of winning the funding she needs if she believes in God, since (for the sake of argument) there are no other funding bodies that S can approach to seek funding for her research program. Suppose also that S's planned research program will result in significant contributions to knowledge about matters of great importance, and that these contributions are unlikely to occur otherwise. Also suppose that the funding body is extremely good at spotting phony applicants; they won't believe that S believes in God unless she genuinely does. Finally, suppose that $\mathrm{S}$ does not currently believe in God and never has.

\footnotetext{
5 This suggestion echoes an influential thesis in Mill's On Liberty (1859), a contemporary version of which is espoused by Kitcher (1993); roughly, that the epistemic aims of communities of inquiry are furthered by doxastic conflict, and that unorthodox beliefs are therefore epistemically beneficial in these communities. Recent work in psychology (e.g. Duarte et al. forthcoming) purports to show that social scientific research is improved by doxastic diversity in the academy, in a way that ostensibly mirrors this Millian thesis.
} 
Now, is it epistemically rational for $\mathrm{S}$ to adopt a belief in God in this case, in view of the epistemic benefits that stand to be gained? Berker says: obviously not (2013: 364). Indeed, the obviousness of the irrationality of believing for this reason is used by Berker to illuminate what he sees as a larger set of problems that arise in formulating norms of epistemic rationality in consequentialist terms. Epistemic consequentialists will treat the rationality of a belief about $\mathrm{P}$ as hinging on whether the possession of this attitude conduces to true belief in general, not just whether it is an optimal appraisal of P's likely truth value, in view of the evidence. This then licenses the kind of trade-offs in which S's evidentially unsupported belief can be endorsed as rational because it will causally lead to people coming to have true beliefs later on. But on Berker's view, such trade-offs are 'beyond the pale' of epistemic rationality (Ibid: 363). When assessing the epistemic merits of a belief, he says, it is strictly irrelevant whether that belief conduces to the attainment of true belief and the avoidance of false belief in propositions other than the one whose status is the focal point of the appraisal (Ibid: 365). To treat such reasons as epistemic reasons, according to Berker, is to fail to respect the 'separateness of propositions'. It means regarding our judgments about whether it's rational for A to believe $\mathrm{P}$ as being grounded in very general desiderata - e.g. people believing more truths overall - whereas, so he maintains, such judgments categorically must be grounded in how A has assessed her first-order P-relevant evidence. ${ }^{6}$

In a paper that explores the prospects for modeling epistemic rationality on decision theory, Hilary Greaves arrives at a similar conclusion, suggesting that some element of our intuitive notion of epistemic rationality is ultimately incompatible with a consequentialist formulation of epistemic norms of belief. Any formulation of epistemic norms which encodes the notion that it's rational to hold a belief that maximizes epistemic utility overall, will - absent the introduction of an ad hoc side constraint - endorse the rationality of accepting 'epistemic bribes', in which a person is induced to reject belief in a proposition for which she has conclusive evidence in order to promote global epistemic benefits. According to Greaves, then, we have

No theory that recovers the obviously correct result that an agent (epistemically) should retain credence 1 in propositions for which she has conclusive evidence, even in the face of 'epistemic bribes'. The reason

\footnotetext{
${ }^{6}$ One way to concede the intuitive thrust of Berker's example, while resisting his larger general claim (i.e. against consequentialist formulations of epistemic norms) is to, like David (2014), hold a version of epistemic consequentialism in which beliefs are credited for realising good epistemic states of affairs, but not if they causally promote those states, only if they constitutively realise those states. This is not the route we want to take, however, because unlike David, we think beliefs which causally promote epistemically valuable states of affairs can be credited with (a certain kind of) epistemic reasonableness, by virtue of this causal effect.
} 
this is difficult to recover... is, heuristically, that a decision-theoretic utility function always assesses epistemic utility globally, and hence will always be open to the move of increasing overall expected utility by making a sacrifice of a relatively small number of propositions; our intuitive notion of epistemic rationality, meanwhile, does not seem to exhibit this willingness. (Greaves 2013: 952)

In different ways, both of these authors are suggesting that our intuitive notion of epistemic rationality entails that what one ought to believe about a given proposition is entirely determined by one's reasons for thinking that that particular proposition is true or false. If we start to allow that people's doxastic attitudes may be adopted for strategic reasons, with a view to increasing the preponderance of true beliefs per se, we will violate the constraints that are imposed by that particular conception of epistemic rationality. Granted, we might have all-things-considered reasons to violate those constraints and adopt doxastic attitudes for strategic reasons. But our notion of epistemic rationality will not - by its nature cannot - endorse such infringements.

\subsection{Organising our intuitions about the atheist scientist}

The intuitions that Berker is seeking to elicit in his discussion of ATHEIST SCIENTIST are difficult to resist. It does seem paradigmatically epistemically irrational for $\mathrm{S}$ to believe in God in order to win research funding that is expected to result in epistemic benefits further down the line, and that's true even if those benefits are of immense significance by S's own lights. But there is an oversupply of reasons that favour Berker's intuitive verdict. So before we grant Berker's claims about the duty to respect the separateness of propositions, and about the untenable character of consequentialist approaches to epistemic rationality, we first have to identify the other sources of irrationality that would be manifested in S's belief in God in ATHEIST SCIENTIST, and try to bracket-off their influence on our wider judgments about the sense in which it is or isn't apt for people to hold their beliefs in a way that's sensitive to the consideration of indirect epistemic benefits.

One problem with S believing in God is that this seemingly must involve her holding a belief about $\mathrm{P}$ that conflicts with her own appraisal of the P-relevant evidence. S is an atheist in the first place, so we may surmise, because she sees this as the doxastic stance vis-à-vis God's existence that the evidence recommends. If that is S's judgment, and if S then adopts a belief in God based on a strategy which is aimed at maximising valuable epistemic outcomes globally, then she will, at a minimum, be left with conflicting beliefs about (i) the question of God's existence and (ii) the probative force of the evidence vis-à-vis God's existence. 
Another related problem with S believing in God in ATHEIST SCIENTIST is that it seems that this will involve some kind of disingenuous willing of belief. If S's appraisal of the relevant evidence leads her to think that 'God exists' is likely false, then - given a plausible view about belief's non-voluntary nature - this simply entails, ipso facto, that S doesn't believe in God. Maybe S can pretend to believe in God, and cajole herself into thinking this pretence represents her beliefs. But this will be intellectually fraudulent, and in any case, it will leave S's real beliefs untouched. S's belief in God would have to be irrational, then, in Berker's example, since the only way for her to induce this belief in herself would be via some sort of self-delusion. ${ }^{7}$

It doesn't follow from either of the above points, though, that indirect epistemic reasons for belief are not epistemic reasons, in this case or in others. Consider a modified version of Berker's example.

PERMISSIVE SCIENTIST. The same conditions obtain as in the previous case $-\mathrm{S}$ must be a theist in order to win funding that will result in major epistemic benefits, etc. - except that, while $\mathrm{S}$ does not believe in God, her judgment about the evidence's probative force, vis-à-vis God's existence, is such that she sees both theism and non-theism as rationally permissible stances on the question of God's existence. ${ }^{8}$ Suppose, then, that in PERMISSIVE SCIENTIST, S takes account of the valuable epistemic consequences that are much more likely to ensue for herself or others if she believes in God (and wins her research grant etc.), and that consideration of this matter compels her - in a Pascalian spirit - to undertake practices that are likely to result in her undergoing a change in her views, from what is, by her lights, one rationally permissible doxastic attitude given the evidence (namely, non-theism) to what is, by her lights, an alternative rationally permissible doxastic attitude given the evidence (namely, theism). Granted, this doesn't settle the question of

\footnotetext{
${ }^{7}$ On this point see for instance David Owens's suggestion, in a discussion of truth as the aim of belief, that this subject won't count as believing $\mathrm{p}$ at all unless he adopts this belief with the aim of believing it only if it is true (Owens 2003: 288).

${ }^{8}$ Roger White (2005) argues against the intuitively plausible Permissivist idea by offering possible ways to defend the Uniqueness Thesis, which is the claim that there can never be more than one rationally permissible doxastic attitude a person may hold towards a particular proposition, given a particular body of evidence. But the radically strict notion of epistemic rationality that comes with Uniqueness and the rejection of Permissivism makes it an implausible and unattractive view (see Kelly 2014, Kopec and Titelbaum forthcoming), and one which, at any rate, we'll assume can be set aside for the purposes of this paper. At the very least, Permissivism is the more favoured view in the literature. Note, however, that there's a particular view of evidence, namely, that evidence is never fully shared, which might make it possible to accommodate the intuitions that favour Permissivism while defending a strong version of Uniqueness. For all we say here, it's possible to believe that Uniqueness holds in possible worlds where ideally rational agents share exactly the same evidence, but that since evidence is never fully shared, de facto Permissivism holds for all real-world purposes.
} 
whether the considerations whose normative force $S$ is responding to in this should ultimately be conceived of as epistemic or pragmatic reasons for her to favour theism. Our point here is just that if there is something epistemically unacceptable about S's favouring of theism in PERMISSIVE SCIENTIST, the unacceptability can't be due to S's belief conflicting with her appraisal of the evidence's probative force, nor due to S having disingenuously willed herself to believe, since neither factor figures in the scenario. It may be a rationalitydefeating feature of a belief - perhaps a decisively rationality-defeating feature - that it conflicts with the agent's assessment of the probative force of the evidence. However, it is consistent with this to allow that, wherever this disqualifying condition doesn't hold, beliefs that are informed by a strategic consideration of what's likely to maximise indirect epistemic benefits are, or at least can be, counted as epistemically rational. ${ }^{9}$

At this point one might object that although S doesn't think theism is false, in light of the evidence, in Permissive Scientist, she also doesn't think it's true. Perhaps, then, Berker's complaint about believing against the evidence could be reformulated, so that the claim is that it's irrational for $\mathrm{S}$ to try to get herself to believe something she doesn't think is true, in light of the evidence. ${ }^{10}$ It seems to us, however, that for this objection to really work, one would have to deny Permissivism outright. Permissivists defend the plausible view that in at least some situations there is more than one rationally permissible doxastic attitude that can be held towards a given proposition, given a certain body of evidence. By definition, the Permissivist regards it

\footnotetext{
${ }_{9}$ As a variation on the ATHEIST SCIENTIST, suppose $\mathrm{S}$ were offered a pill that will make her believe in God and also believe that this is the belief that the evidence supports, and suppose that the anticipated benefits of S's theism are the same as in the original example. This variation eliminates the worry about S's beliefs conflicting with her beliefs about the evidence's probative force, and in that sense it looks like we should be more willing to accept that there's an indirect epistemic reason in favour of theism for S in this scenario, even though it intuitively seems like taking the pill is even more egregiously irrational in this scenario than in the original scenario. But whether or not this intuition is worth respecting depends on what S's prior assessment of the evidence's probative force was. If, at time $t_{1}, S$ 's appraisal of the evidence's probative force allowed that both theism and non-theism were rationally permissible doxastic stances, then taking the pill will result in $\mathrm{S}$ having a view of the evidence's probative force at time $\mathrm{t}_{2}$ that, by $\mathrm{S}$ 's lights at time $\mathrm{t}_{1}$, was a rationally permissible assessment of the evidence's probative force. By contrast, if S knows at $\mathrm{t}_{1}$ that the pill will cause her to have a belief at $\mathrm{t}_{2}$ about the evidence's probative force which is, by S's lights at $\mathrm{t}_{1}$, rationally impermissible, then there does appear to be something unacceptably self-deceptive about taking the pill, regardless of the epistemic benefits that are in the offing. Our point is just that there are scenarios involving these sorts of wholesale 'doxastic overhauls' that avoid this kind of self-deception. (While White (2005) has argued that pill-taking cases like the one sketched here show that Permissivism is untenable, we can't answer his argument here, except to note, as others have (see note 8), the significant costs that come with rejecting Permissivism.) 10 We're grateful to an anonymous referee for bringing this objection to our attention.
} 
as rationally permissible for an agent with the relevant evidence, in such a case, to hold any of the permissible attitudes. In PERMISSIVE SCIENTIST, then, it would misrepresent S's perspective to say that she's nurturing belief in a proposition whose truth she doesn't accept. The more apt description would be to say that she's nurturing a belief which, given the relevant evidence, (i) might well be true, by her own lights, and (ii) whose rational permissibility she has affirmed all along. The only way to insist on the irrationality of these kinds of judgments is to reject the Permissivist's characterisation of S's initial appraisal of the evidence. Granted, someone may doubt that the evidence is ever 'permissive' when it comes to belief in God. But our point that it's possible to be sensitive to indirect epistemic reasons, without disingenuously believing against one's own appraisal of the evidence - should still hold, as long as there are some permissive cases. ${ }^{11}$

To characterise indirect epistemic reasons for belief as epistemic reasons is not to say that people should delusionally gull themselves into having beliefs that conflict with their views about the evidence's probative force. It's just to say that where an agent identifies some spectrum of rationally permissible doxastic attitudes in response to some body of evidence, and where she has some ability to influence what doxastic attitude she holds among that range of options, then, to the extent that she has reason to believe that her holding doxastic attitude $\mathrm{X}$ will have better global epistemic consequences than her holding doxastic attitude $\mathrm{Y}$, she has a reason - one that may be aptly characterised as an epistemic reason - to favour X over Y.12

\footnotetext{
11 We also believe that Berker's case is not dependent on Uniqueness. So the crux of our objection to Berker does not reduce to the Permissive versus Uniqueness debate. That is, Berker's position is (to all appearances) consistent with Permissivism.

12 Another problem with S believing in God in ATHEIST SCIENTIST is that S surely cannot take herself to know that her theism will result in the epistemically valuable consequences that it would need to, in order for $\mathrm{S}$ to actually have an indirect epistemic reason for theism. More generally, one might say, it's an unwise policy to hold beliefs that are not, by one's own lights, adequately supported by the evidence, in the expectation that this will result in good epistemic consequences later on. We agree. But this is consistent with maintaining that to whatever extent one is justified in believing that one is in a scenario where nurturing beliefs for strategic reasons will be epistemically beneficial overall, one has a reason - which may be aptly characterised as an epistemic reason - to nurture the relevant beliefs. It's also worth noting here that plenty of epistemologists take the phenomenon of indirect epistemic benefits seriously, and treat them as an actual (and apprehensible) part of our intellectual lives, and not merely a philosopher's hypothetical; for examples see Moffett (2007), Christensen (2007), Conee (2009), Elgin (2010), Feldman (2011), and of course Berker (2013).
} 


\subsection{Two kinds of epistemic reasons}

We aren't trying to deny that there is an important difference between a person believing P because her appraisal of the evidence indicates that $\mathrm{P}$ is true, and a person believing $\mathrm{P}$ because indirect epistemic benefits are in the offing if she does so. It's entirely reasonable, moreover, to want the difference between these two kinds of reasons for belief to be reflected in our classificatory terminology. What we oppose is the framing of this as a distinction between epistemic and pragmatic reasons. In a case like PERMISSIVE SCIENTIST, the valuable outcomes whose realisation gives $\mathrm{S}$ a reason to believe $\mathrm{P}$ are, after all, epistemically valuable outcomes. ${ }^{13}$ Where such cases are in the frame of discussion, we think that the discussion will be better served by a distinction between direct and indirect epistemic reasons. This terminology provides a better indication of the nature of the conflicting desiderata that are in play in a case like PERMISSIVE SCIENTIST. The choice that $\mathrm{S}$ is facing in this case isn't whether to ignore the requirements of epistemic rationality for the sake of pragmatic considerations. Rather, the choice she's facing is whether to deprioritise the demands of direct epistemic rationality, and to instead prioritise indirect epistemic considerations. In such a scenario, if S did successfully nurture a belief in God, then even if we still wanted to criticise the (direct) epistemic rationality of her beliefs, we also can (and should) leave ourselves room to concede that there are reasons favouring S's theism that are epistemic reasons of a certain sort - again, indirect epistemic reasons - and not merely pragmatic reasons.

In recent work defending the 'equal weight view' about the epistemic significance of disagreement, ${ }^{14}$ Jonathan Matheson posits a distinction between 'non-instrumental' and 'instrumental' epistemic reasons that is similar to our proposed distinction between direct and indirect epistemic reasons. One of the concerns that arises for the equal weight view, insofar as it recommends suspension of judgment about a range of issues, is that it may lead towards general skepticism. In response to this worry, Matheson suggests that there can be instrumental epistemic reasons for remaining steadfast in one's views in the face of peer disagreement, the consideration of which should arrest this lapse into skepticism. For example, with regards to some types of research or inquiry, progress is "more likely to happen when individuals believe their controversial views and

\footnotetext{
13 Although to be clear, we're not saying that the only reasons that have sway in guiding the PERMISSIVE SCIENTIST'S beliefs are indirect epistemic reasons. In this example, the scientist is supposed to have thought about the evidence and arguments for theism, and her doxastic attitude vis-à-vis theism is supposed to remain sensitive to her judgments about the probative force of that evidence. 14 The equal weight view being, roughly, the view that one ought to significantly revise one's belief that $\mathrm{P}$ in the face of peer disagreement about P; for notable defences of this kind of view, see Elga (2007) and Christensen (2007).
} 
when there is a diversity of opinions being defended" (Matheson 2015: 145). The reasons this consideration generates are, according to Matheson, instrumental epistemic reasons for belief, because

They do not affect what the subjects are justified in believing about the controversial propositions while they are still controversial. Believing the controversial propositions can be part of a good diachronic strategy for attaining true beliefs while avoiding false ones, but subjects who so believe fail to be epistemically justified in their beliefs at the time (Matheson 2015: 145).

Matheson's distinction between synchronic and diachronic ways of conceiving of epistemic justification is a useful one. Synchronic justification "concerns the current time and what doxastic response right now would do you best with respect to these goals right now"; diachronic justification, by contrast, "concerns later times and what doxastic response right now would do you best with respect to these goals in the long run" (Ibid: 146). The equal weight view is the appropriate view on the epistemic significance of disagreement, Matheson suggests, if and insofar as we're thinking about epistemic justification synchronically. But it's consistent with this to say that synchronic and diachronic factors can aggregate into all-things-considered epistemic reasons, and that - because of the indirect epistemic benefits that disagreements can contribute to - the all-thingsconsidered epistemic reasons that are in play in cases of peer disagreement sometimes (or often) recommend a steadfast (i.e. skepticism-resistant) response to peer disagreement. Formulated in our preferred terminology, Matheson's claim is that consideration of the indirect epistemic reasons that obtain in a particular case can affect what's epistemically rational for someone to believe in the face of peer disagreement.

In response to all this, someone might concede that there is some sense in which indirect epistemic benefits generate epistemic reasons of a certain kind, while at the same time insisting that responding well to direct epistemic reasons (as we call them) is really what epistemic rationality is all about. Our claim in $₫ 2.2$ was that in a scenario like ATHEIST SCIENTIST, it's possible to bracket off the main factors that lead us to want to deny the epistemic rationality of nurturing beliefs that promote indirect epistemic benefits. Being sensitive to the possible epistemic benefits of one's beliefs doesn't necessarily lead to self-deception or internal conflict. But even if this is right, the critic may still say that the person who forms a belief in P based on her appraisal of the first-order, P-relevant evidence, while paying no mind to other considerations - in Berker's terms, the person who honours 'the separateness of propositions' - shows a kind of dutiful respect for the evidence that is especially meritorious. However, we don't see why the idea of a duty to respect the evidence should bring things to justificatory bedrock. We can still ask why it's meritorious to dutifully respect the evidence. And one 
plausible explanation is that epistemically valuable outcomes (e.g. people believing truths and disbelieving falsehoods) will be more effectively realised on the whole when categorical doxastic precepts - such as: 'form beliefs based on what the first-order evidence shows, and nothing else' - are accepted and followed. ${ }^{15}$ Insofar as something like a rule-consequentialist interpretation of strict evidentialist norms is viable, there isn't any need to insist upon a stark divide, as Berker does, between (i) belief-formations that give some consideration to possible indirect epistemic benefits, and (ii) belief-formations that eschew any such consideration, so as to denounce the former as being beyond the pale of epistemic rationality. Granted, this is precisely the kind of epistemic consequentialism that Berker critiques. The point is that once we have bracketed off the various complicating factors discussed in $\$ 2.2$, the remaining intuitive force that's animating Berker's separateness of propositions norm seems amenable to a rule-consequentialist interpretation. And because of this, we have the option of categorising indirect epistemic reasons as a bona fide species of epistemic reasons for belief, rather than being forced to relegate them into an entirely different (i.e. pragmatic) normative genus.

We've suggested that intuitions about the deontological nature of epistemic norms are amenable to a rule consequentialist interpretation. Much more would need to be said, though, in order to confidently assert this. Thinking of parallels in ethical theory, some authors argue that rule consequentialist norms boil down to deontological norms (e.g. Howard-Snyder 1993), while others argue that rule consequentialism collapses back into act consequentialism (Smart 1956). If we're after a consequentialist epistemic framework, but one which makes room for non-consequentialist evidentialist norms - by 'going indirect', à la rule consequentialism then we'll need to think about how such critiques of rule consequentialism play out in the epistemic domain. We might also have to consider whether deontological understandings of epistemic norms rely on something analogous to the idea of 'agent-relative reasons' in ethics. Just as some ethicists deny that any of us have impersonal reasons to promote the ethical good (e.g. Nagel 1986, Darwall 2006), so too one might deny that we have impersonal reasons to promote the epistemic good. If this is how we conceive of the roots of nonconsequentialist epistemic norms, then elaborating the kind of view we've sketched here will involve saying something about what it means to approach epistemology in an agent-neutral frame of mind - 'from the

\footnotetext{
15 Percival (2002) sketches the prospects for a rule consequentialist epistemic norm along these lines. Greaves (2015: 37) makes a brief but intriguing suggestion, which complements our response to Berker here, that insofar as a non-consequentialist ethos is part of our intuitive notion of epistemic rationality, as invoked by Berker, this may owe to the fact that public advocacy of non-consequentialist epistemic rules and the internalisation of such rules tend to result in better epistemic outcomes.
} 
point of view of the universe', to borrow that well-worn and evocative phrase. ${ }^{16}$ An assessment of the general prospects for epistemic consequentialism is a task that several other authors have taken up recently. ${ }^{17}$ But any detailed elaboration of the above is beyond the scope of the present paper. In any case, we acknowledge that in our defence of why indirect epistemic reasons for belief can properly be regarded as epistemic reasons, and not mere pragmatic reasons, we've assumed that an epistemic consequentialist ultimately will have satisfactory positions to take in response to issues and questions like the ones we have mentioned here.

\subsection{An argument from interpersonal normative parity}

Up to this point we've been responding to different kinds of worries, all of which seem to favour the view that we should conceive of indirect epistemic reasons as mere pragmatic reasons for belief. But we think there is also an interesting positive case to be made for thinking of indirect epistemic reasons as bona fide epistemic reasons for belief. Indirect epistemic reasons, we want to suggest, exhibit a type of 'interpersonal normative parity' that is characteristic of epistemic reasons for belief in general, but not of pragmatic reasons.

First, consider how pragmatic reasons for belief get their normative purchase on agents. Where $\mathrm{R}$ is a pragmatic reason for $\mathrm{A}$ to believe $\mathrm{P}$, this by itself does not make it the case that $\mathrm{R}$ is also a pragmatic reason for person B to believe P. R's normative force only carries over like this if it happens that B shares the aims or interests by virtue of which $\mathrm{R}$ has its pragmatic normative force for A. So, for example, suppose $\mathrm{A}$ has a pragmatic reason to believe P because this makes it easier for her to get along with her family. This pragmatic reason - A getting along with her family - will have little or no purchase on B, insofar as getting along with A's family (presumably) doesn't figure among B's aims or interests. In this sense pragmatic reasons for belief only exhibit a relatively weak and relatively contingent form of interpersonal normative parity.

By contrast, where evidence E constitutes a bona fide epistemic reason for A to believe $\mathrm{P}$, it also, ceteris paribus, constitutes an epistemic reason for B to believe P. Or to express this in a more qualified way, where evidence $\mathrm{E}$ is an epistemic reason for $\mathrm{A}$ to believe $\mathrm{P}$, the question of whether $\mathrm{E}$ is also an epistemic reason for B to believe P doesn't hinge on what A's and B's respective aims and interests are, nor the extent to which they coincide. For example, suppose A cares a great deal about people having true beliefs on the question of God's existence, whereas B doesn't care about this at all. Irrespective of this disparity in A's and B's interests

\footnotetext{
${ }^{16}$ We're grateful to an anonymous referee for pressing us to consider these points.

${ }^{17}$ See for example Talbot (2014), Ahlstrom-Vij and Dunn (2014), and Rinard (forthcoming).
} 
and concerns, the relevant epistemic considerations (e.g. a priori and a posteriori arguments for and against theism) constitute reasons for B to believe that God does or doesn't exist, just as much as they constitute epistemic reasons for A to believe this. Epistemic reasons for belief thus exhibit a robust form of interpersonal normative parity - robust in the sense that the kind of demands that they generate for agents are ostensibly impervious to disparities in the aims and interests of different agents. We aren't prepared to stake a claim here about the weight of epistemic reasons for belief. We aren't committed to any particular view about the nature of the blame that one is liable to receive as a result of, say, failing to appropriately interpret one's evidence. All we're saying is that one cannot evade the demands of epistemic reasons by renouncing an interest in those demands. We're answerable to norms of rational belief regardless of whether we want to be. ${ }^{18}$

Having observed this general difference in the interpersonal normative parity of epistemic reasons and pragmatic reasons, our claim is that it's a consideration in favour of the appropriateness of classifying indirect epistemic reasons as epistemic reasons, rather than pragmatic reasons, that these kinds of reasons for belief exhibit the more robust form of interpersonal normative parity. In circumstances where more truths will be believed in domain $\mathrm{D}$ provided that someone believes $\mathrm{P}$, both $\mathrm{A}$ and $\mathrm{B}$ are given an indirect epistemic reason to believe P. And this interpersonal normative parity obtains even if it happens to be the case that $\mathrm{A}$ is deeply concerned about the prevalence of true belief in domain D, whereas B doesn't care at all about this. As an illustration of this, consider the story of Twelve Angry Men. One dissenting juror believes the defendant to be innocent, even though all the other jurors believe that the defendant is guilty. This one juror's dissent forces the jury to discuss and reassess the evidence, and as a result of this more truths about the details and circumstances of the crime are (eventually) believed by all the jurors. In a parallel scenario, in which the social epistemic dynamics of consensus and dissent were operating in a similar way (and recognised as such), but where none of the jurors initially had any doubts about the guilty verdict, every juror would have an indirect epistemic reason to believe that the defendant was innocent, because any of them believing the defendant to be innocent would ultimately result in more truths about the case being believed. The (indirect) epistemic reason that's in effect in this case applies to all the agents, just as a new item of relevant evidence would be a (direct) epistemic reason for all agents to alter their views. The interpersonal force of both kinds of reasons owes to the fact that all agents have epistemic reasons to aspire to truth, regardless of their personal aims and

\footnotetext{
18 Of course one might question this. But we think it's an assumption shared by everyone engaged in these debates.
} 
interests. In short, an epistemic reason that tells in favour of believing $\mathrm{P}$ has its (epistemic) normative force for different agents irrespective of their contingent aims and interests. And this is the case for indirect epistemic reasons, we maintain, in much the same way as it's the case for direct epistemic reasons.

\section{Indirect Epistemic Benefits and Religious Belief}

\subsection{Religion, diversity, and unorthodoxy}

As indicated in the introduction, we now want to ask how reflection on indirect epistemic reasons for belief affects the rational standing of beliefs about matters of religion. We believe there are at least some conditions under which consideration of indirect epistemic benefits supports some religious belief, subject to caveats which reflect the issues we discussed in $\$ 2.2$, relating to self-deception and self-contradiction.

We'll begin by discussing several examples that are close to home for philosophers. Consider the major contributions to knowledge that have been made, in post-war Anglophone philosophy, by philosophers whose work is partly motivated by the aim of substantiating or clarifying some aspect of their prior religious convictions. Some of that research has been done by authors who self-consciously situate their work in the sub-discipline of philosophy of religion. For instance, in attempting to defend the view that a certain kind of religious experience justifies theistic belief, William Alston (1991) formulates an influential defence of a view that has general and wide-reaching epistemological ramifications, namely, that there is no non-circular way to defend the justificatory import of sensory perception. In a nearby region of the philosophical map, Alvin Plantinga's work, which broadly aims at defending the warranted status of Christian theism, builds in novel contributions to prior understandings of (i) externalist epistemologies founded on a conception of a proper functioning perceptual apparatus (1993), and (ii) the concept of beliefs being properly basic, i.e. justified on non-inferential grounds (2000). Outside of research that's self-consciously situated in philosophy of religion, Elizabeth Anscombe's Catholic faith was a discernible guiding force in her ground-breaking work on the nature of intention (1957), and in her (related) influential critiques of midcentury ethical theory (1958), both of which germinated major research programs that have expanded our breadth of understanding in ethics and philosophy of action. Obviously we shouldn't pretend to have any definitive biographical knowledge of what motivated these particular individuals in their work. Still, there are reasons - plausible inferences, and textual 
evidence $^{19}$ - in light of which it's reasonable to think that the ideas and arguments these authors gave us, and the further knowledge their research agendas generated, owe a large debt to these authors' prior religious convictions, and to the (entirely natural) impulse that most thoughtful people have to want to show that their deepest convictions are underwritten by a coherent and credible set of ideas about the world.

To the extent that having prior religious convictions has led to some philosophers producing novel ideas and arguments, and thereby contributing to good epistemic outcomes, this is partly an upshot of mundane facts about the sociology of the philosophical academy, namely, that at a particular time it was populated nearly entirely by people who regarded Catholic moral doctrine and Dutch Reformed theology as views that didn't merit any serious intellectual consideration. ${ }^{20}$ In short, the indirect epistemic benefits of religious belief in this domain owe to the ostensible absence of religious belief within the domain, and to the familiar Millian principle that in an intellectually homogenous group, adding people with unorthodox views is epistemically salutary, since the ensuing disputes tend to reduce the rate of unthinking acceptance of false orthodoxies by people in that group. But the general upshot of the above is not specific to religious belief. Where there's no-one who believes $\mathrm{P}$ in a group or social environment, then having someone around who believes $\mathrm{P}$ is liable to have some benefit on some of the epistemic goals - the acquisition of knowledge, the transmission of true beliefs - for that group or environment. So, where everyone's an atheist, the introduction of a religious believer is epistemically salutary. But equally, where everyone's a religious believer, the introduction of an atheist is epistemically salutary. Similar points can be made along different axes. Where everyone's a moral realist, the introduction of a nihilist is salutary. Where everyone thinks alternative medicine is a sham, the introduction of a thoughtful defender of alternative medicine is salutary. Are there any reasons to think that there are indirect epistemic benefits that result from religious belief, beyond those reasons that obtain under particular demographic conditions, as a result of the general point noted here?

One reason why indirect epistemic benefits might be generated by people's adherence to religious belief-systems in particular, is the fact that religious belief-systems tend to be, as the term suggests, systematic in their linking together of propositions in metaphysics, epistemology, ethics, etc. The intellectual effort that's involved in trying to get a complicated set of views across these different domains to 'hang together' will tend

\footnotetext{
${ }^{19}$ In Plantinga's 'Advice to Christian philosophers', for instance, he overtly enjoins Christian philosophers to work on issues that interest them as Christians first and foremost, instead of being guided by the priorities of the broader academic community.

${ }^{20}$ Religious non-belief continues to be the majority view in today's philosophical academy; see Bourget and Chalmers 2014.
} 
to elicit intellectual creativity - in argumentation, and in the elaboration of conceptual frameworks - that may result in novel contributions to knowledge, even if it's just knowledge of the logical cartography of the terrain being explored by the proponent of a particular religious belief-system. In a manner that's analogous to how the metrical constraints of a sonnet or a haiku elicit aesthetic ingenuity, the constraints that come with trying to reconcile the elements of the religious belief-systems that one identifies with may elicit intellectual ingenuity. In general, where one sees that one's beliefs are unorthodox, one may recognise that there are indirect epistemic benefits that stand to be gained by one's believing as one does. But where one recognises that one's view are unorthodox and that they have a complex systematicity that needs working out, one may see a double indirect epistemic benefit in the offing: not just in challenging the easy acceptance of debateable orthodoxies among one's opponents, but also in the work that one will have to do in order to give an account, to an antecedently unsympathetic audience, of how the different parts of one's belief-system coalesce and interact.

None of this is to suggest that it would be rational for a person to try to nurture belief in a religious belief-system where she judges that the relevant evidence and arguments manifestly fail to rationally support that belief-system. As we said in $\$ 2$, in discussing the scenario of ATHEIST SCIENTIST and contrasting it with the reformulated scenario of PERMISSIVE SCIENTIST, the type of case in which indirect epistemic reasons may properly get a grip on some agent, A, is where A antecedently judges that the probative force of the relevant evidence makes belief in P rationally permissible, and where this leads A to favour this belief-state over some other belief state (like, say, agnosticism about $\mathrm{P}$ ) which she also regards as a rationally permissible response to the evidence. If recognition of the potential indirect epistemic benefits of holding some religious belief leads someone to delusively nurture a belief that by her own lights represents a rationally impermissible assessment of the evidence, this certainly would be irrational. But if it leads someone to nurture a belief that by her own lights represents a rationally permissible assessment of the evidence, there's nothing amiss about that. In at least some cases, then, indirect epistemic reasons rationally support the nurturing of religious beliefs.

\subsection{Taking account of indirect epistemic reasons as reasons for belief}

We concede that the reflective mindset involved in trying to take account of indirect epistemic reasons is a peculiar one. Someone might even deny that there's any coherent notion of 'taking account of or 'being influenced by' such reasons to be provided. According to Jonathan Adler (2002), there is no psychologically workable way to approach belief-formation apart from the one in which we form beliefs based solely on our 
ingenuous assessment of the evidence. Indeed, this is why epistemic norms operate in a distinctive - he insists, wholly evidentialist - normative domain. Beliefs are not acts, they are representations of how we take the world to be. And we cannot take the world to be any way other than how we in fact take it to be. Brian Talbot, in defending a form of epistemic consequentialism that's complementary to our position here, rejects Adler's view on this matter. For Talbot, reasons generated by indirect epistemic considerations and reasons grounded in routine appraisals of evidence can exert their normative force on people's beliefs in harmony with one another, insofar as both kinds of reasons ultimately derive from, and operate in the service of, the same epistemic ends (2014: 615-16). ${ }^{21}$ Although we're sympathetic to this suggestion, we also think it makes matters sound implausibly smooth and simple. Attempting to take account of indirect epistemic reasons while remaining faithful to one's assessment of one's first-order evidence is liable to be confusing. In this respect, paying attention to indirect epistemic reasons for belief does seem to have something important in common with paying attention to pragmatic reasons for belief. In both kinds of cases, the agent's doxastic attitudes become sensitive to her consciously apprehensible motivations, and so in both kinds of cases trying to take these reasons into account involves a jarring interruption of the unmotivated (or not-consciously motivated) observations and appraisals that are the etiology of normal, evidence-based belief. One might even suggest that to categorise indirect epistemic reasons as bona fide epistemic reasons, as we do, is to overlook this point of similarity in how agents consciously take account of both kinds of reasons as reasons.

On the other hand, though, to classify indirect epistemic reasons as merely pragmatic reasons is to suggest that they are - like other pragmatic reasons for belief, such as what's comforting to believe; or what's ego-boosting to believe - a type of consideration that ought to be ignored by intellectually serious truth-seekers. And that, we have argued, is a mistake. Once we start thinking about the roles we occupy in communities of inquiry, and about how our beliefs can contribute to good and bad social epistemic dynamics - in other

\footnotetext{
${ }^{21}$ Talbot uses the term 'truth-promoting non-evidential reasons' to refer to what we call 'indirect epistemic reasons'. What Talbot's account emphasises, helpfully, is the way that an understanding of indirect epistemic reasons as bona fide epistemic reasons is embedded in certain consequentialist ways of thinking about epistemic norms that are already widely accepted among epistemologists. Our strategy differs from Talbot's in that we offer a comparative argument: indirect epistemic reasons should be understood as bona fide epistemic reasons because they can more be plausibly characterised as epistemic reasons than pragmatic reasons for belief. Similar to Talbot, though, we don't purport to defend epistemic consequentialism from first principles, so much as to show how certain putative problems that are supposed to make epistemic consequentialism untenable can in fact be avoided.
} 
words, once we start doing (a certain kind of) social epistemology - we are already, whether we like it or not, contemplating the indirect epistemic consequences of our beliefs, and conducting our intellectual business in a way that's liable to be influenced by this consideration. When someone tries to more self-consciously take these indirect epistemic reasons into account, she shouldn't be thought of as weakening in her commitment to epistemic rationality, and letting her beliefs be guided by mere pragmatic concerns. Attempting to include indirect epistemic reasons in one's reflective considerations should be thought of as a commendable effort to pay attention to all the epistemic reasons for belief that apply in relation to the issue at hand.

Still, the question of precisely how an epistemically rational agent could take indirect epistemic reasons into account, and go on forming beliefs that are sensitive to the evidence, but also with this extra consideration in mind, is a difficult one. We conclude with some tentative remarks on this, linking back to the non-evidential arguments for religious belief from $\$ 1$, Pascal's wager and James’s will to believe.

Both Pascal and James advert to pragmatic considerations which, so they claim, favour belief in God. At the same time, both recognise that to really believe in God is to ingenuously think it's true that God exists, and not just to acknowledge the pragmatic reasons that favour thinking as much. And in different ways, both authors try to bridge this gap between pragmatic motive and ingenuous belief by recommending some form of enacted commitment to the beliefs one has (alleged) non-evidential reasons to adopt. Where we've postulated a distinction between having a direct epistemic reason to believe $\mathrm{P}$, and having an indirect epistemic reason to nurture a belief that $\mathrm{P}, 22$ this notion of enacting a commitment to $\mathrm{P}$ - of being a believer in $\mathrm{P}$, as opposed to just having a belief that $\mathrm{P}$ - narrows the gap between these two things. To think of beliefs as enacted commitments is to reject a familiar understanding of how epistemic rationality and practical rationality interact. We don't always start by settling our ideas about what we believe, and then, following that settlement, choose how to conduct our lives. In our efforts to make our beliefs and practices cohere, sometimes the former adjust to fit the latter. Put simply, we work out our beliefs and practices in tandem. Indeed, according to James at least, there are cases in which it's only by undertaking a commitment to certain practices that we'll even encounter all of the evidential reasons that support the beliefs which would make sense of those practices. The very idea of religious belief hinges on action, James says, and if we insist that decisive evidential reasons for belief

\footnotetext{
22 Others have instinctively favoured something similar; see for instance, Kelly's (2003: 634-37) discussion of the difference between epistemic rationality per se, on one hand, and instrumental rationality in the service of one's epistemic goals, on the other.
} 
always have to precede action, à la Clifford, ${ }^{23}$ then - in matters of religion, and in other areas of life as well we cut ourselves off from truths of potentially great significance (James 1912: 29-30). The remedy to this is to allow that people may decide to live in the light of beliefs about whose truth they're uncertain.

Our question, remember, is how an epistemically rational agent can take indirect epistemic reasons into account. In the domain of religion, enacting a commitment to a particular belief may mean spending time with a faith community, or engaging in devotional practices like prayer and meditation, or identifying oneself as a member of the faith and promoting it to others. We don't think that taking account of indirect epistemic reasons will, in general, require agents to regularly perform analogues for all of these. But the third element above - identifying oneself as an adherent of a view and promoting it to others - does seem like a simple and palatable way of enacting a commitment to a belief which one takes to be supported by indirect epistemic reasons. In acting as an advocate for a certain view and signalling one's pro-attitude towards it, one can thereby find oneself becoming more cognisant of the view's rational merits. These things are all to the good, on a Jamesian or Pascalian view, since the point of enacting a commitment to a belief, on such views, is to engage in practices which betoken one's pro-attitude towards that belief, and which simultaneously can make the belief's merits, as a picture of the world, more vivid than they were in the abstract. Much more could be said about all this. Our contention, for now, is simply that there is some sense to be made of the notion of responding to indirect epistemic reasons as reasons, and that a better sense of what this involves might be unearthed by looking at those who favour 'enacted commitment' as an approach to religious belief.

\section{References}

Adler, J. E. 2002. Belief's Own Ethics. Cambridge Massachusetts: MIT Press.

Ahlstrom-Vij, K. and Dunn, J. 2014. A defence of epistemic consequentialism. The Philosophical Quarterly 64: 541-51.

Alston, W. 1991. Perceiving God. Ithaca: Cornell University Press.

Anscombe, G. E. M. 1957. Intention. Oxford: Basil Blackwell. 1958. Modern moral philosophy. Philosophy 33: 1-19.

Berker, S. 2013. Epistemic teleology and the separateness of propositions. Philosophical Review 122: 337-93.

${ }^{23}$ James's will to believe argument was, famously, a rejoinder to Clifford's (1876) claim that it is wrong, always and everywhere, for anyone to believe anything on the basis of insufficient evidence. 
Bourget, D. and Chalmers, D. 2014. What do philosophers believe? Philosophical Studies 170: 465-500.

Christensen, D. 2007. Epistemology of disagreement: the good news. Philosophical Review 116: 187-217.

Clifford, W. K. 1876. The ethics of belief. The Contemporary Review 29: 289-309.

Conee, E. 2009. Peerage. Episteme 6: 313-23.

David, M. 2014. Truth as the primary epistemic goal: a working hypothesis. In Contemporary Debates in Epistemology, $2^{\text {nd }}$ Edition, ed. M. Steup, J. Turri, and E. Sosa, 363-77. Oxford: Wiley-Blackwell.

Darwall, S. 2006. The Second-Person Standpoint: Morality, Respect, and Accountability. Cambridge MA: Harvard University Press.

Duarte, J. L., Crawford, J. T., Stern, C., Haidt, J., Jussim, L. and Tetlock, P. E. 2016. Political diversity will improve social psychological science. Forthcoming in Behavioral and Brain Sciences.

Elga, A. 2007. Reflection and disagreement. Nô̂s 41: 478-502.

Elgin, C. Z. 2010. Persistent disagreement. In Disagreement, ed. R. Feldman and T. A. Warfield, 53-68. Oxford: Oxford University Press.

Feldman, R. 2011. Reasonable religious disagreements. In Social Epistemology: Essential Readings, ed. A. I. Goldman and D. Whitcomb. Oxford: Oxford University Press.

Firth, R. 1981. Epistemic merit: intrinsic and instrumental. Proceedings and Addresses of the American Philosophical Association 55: 5-23.

Fumerton, R. 2001. Epistemic justification and normativity. In Knowledge, Truth, and Duty: Essays on Epistemic Justification, Responsibility, and Virtue, ed. M. Steup, 49-60. Oxford: Oxford University Press.

Greaves, H. 2013. Epistemic decision theory. Mind 122: 915-52.

Howard-Snyder, F. 1993. Rule consequentialism is a rubber duck. American Philosophical Quarterly 30: 271-78.

James, W. 1912. The Will to Believe and Other Essays in Popular Philosophy. London: Longmans, Green, and Co.

Jordan, J. 2014. Pragmatic arguments and belief in God. In The Stanford Encyclopedia of Philosophy (Winter 2014 Edition), ed. Edward N. Zalta, http://plato.stanford.edu/archives/win2014/entries/pragmatic-belief-god/.

Kelly, T. 2003. Epistemic rationality as instrumental rationality: a critique. Philosophy and Phenomenological Research 66: 61240.

2014. Evidence can be permissive. In Contemporary Debates in Epistemology, $2^{\text {nd }}$ Edition, ed. M. Steup, J. Turri, and E. Sosa, 298-311, Oxford: Wiley-Blackwell.

Kopec, M. and Titelbaum, M. 2016. The uniqueness thesis. Forthcoming in Philosophy Compass.

Kitcher, P. 1993. The Advancement of Science. Oxford: Oxford University Press.

Matheson, J. 2015. The Epistemic Significance of Disagreement. New York: Palgrave Macmillan.

Mill, J. S. 1859. On Liberty. London: J. W. Parker and Son. 
Moffett, M. 2007. Reasonable disagreement and rational group inquiry. Episteme 4: 352-67.

Nagel, T. 1986. The View from Nowhere. New York: Oxford University Press.

Owens, D. 2003. Does belief have an aim? Philosophical Studies 115: 283-305.

Pascal, B. 1950. Pascal's Pensées. London: Routledge and Kegan Paul.

Percival, P. 2002. Epistemic consequentialism. Proceedings of the Aristotelian Society Supplementary Volume 76: 121-51.

Plantinga, A. 1984. Advice to Christian Philosophers. Faith and Philosophy 1: 253-71. 1993. Warrant and Proper Function. New York: Oxford University Press. 2000. Warranted Christian Belief. New York: Oxford University Press.

Rinard, S. 2016. No exception for belief. Forthcoming in Philosophy and Phenomenological Research.

Smart, J. J. C. 1956. Extreme and restricted utilitarianism. The Philosophical Quarterly 6: 344-54.

Stanley, J. 2005. Knowledge and Practical Interests. New York: Oxford University Press

Talbot, B. 2014. Truth promoting non-evidential reasons for belief. Philosophical Studies 168: 599-618.

White, R. 2005. Epistemic permissiveness. Philosophical Perspectives 19: 445-59. 